\title{
A formação de juízes: o desafio de formar novas competências
}

Este artigo analisa a atuação da Escola Judicial Desembargador Edésio Fernandes do TJMG no desenvolvimento de competências dos Juízes. Foi realizada uma pesquisa utilizando o método de estudo de caso, a coleta de dados feita através de análise documental e entrevistas semiestruturadas. Os resultados revelaram que a Escola Judicial mineira contribui positivamente no desenvolvimento das competências relacionadas aos conhecimentos técnico-jurídicos, mas os juízes acreditam ser necessário a Escola trabalhar as competências humano-sociais, para o exercício da função. Existe também a necessidade de o juiz acompanhar a evolução tecnológica, mas a pesquisa revelou aspectos dificultadores. Características inerentes às organizações burocráticas como centralização de poder, hierarquia, controle, são transpostas para as salas de aula, dificultando a relação professor-aluno.

Palavras-chave: Formação de Competências; Qualificações profissionais; Aprendizagem Organizacional; Desenvolvimento Organizacional; Organização Judiciária.

\section{Training of judges: the challenge of forming new competences}

This article analyzes the performance of Judicial School Judge Edésio Fernandes of the TJMG in the development of Judges' competences. A research was carried out using the case study method, data collection through documentary analysis and semi-structured interviews. The results revealed that the Minas Gerais Judicia School contributed positively to the development of competencies related to technical-legal knowledge, but judges believe that it is necessary for the School to work human-social competences for the exercise of the function. There is also a need for the judge to keep up with technological developments, but research has revealed some difficulties. Inherent characteristics of bureaucratic organizations such as centralization of power, hierarchy, control, are transposed into the classrooms, hindering the teacher-student relationship.

Keywords: Competence Development; Professional Qualifications; Organizational learning; Organizational Development; Judiciary Organization.

\section{Topic: Gestão Pública}

Reviewed anonymously in the process of blind peer.

Cláudia Suely de Almeida Campos

Faculdade Presidente Antônio Carlos de Conselheiro Lafaiete, Brasil http://lattes.cnpq.br/0555755331901940

claudiasuely@gmail.com
Received: 11/05/2017

Approved: 10/07/2017
Referencing this:

CAMPOS, C. S. A.. A formação de juízes: o desafio de formar novas competências. Revista Brasileira de Administração Científica, v.8, n.2, p.147-162, 2017. DOI: http://doi.org/10.6008/SPC2179$\underline{684 X .2017 .002 .0010}$ 


\section{INTRODUÇÃO}

Estamos vivenciando um período de profundas mudanças tecnológicas, econômicas e sociais da história. Nos próximos anos, mudanças ainda mais rápidas prometem acontecer. Elas vêm surgindo de uma transformação profunda na economia global. No setor privado, analisa Guimarães (2000), a competição decorrente das mudanças faz com que as empresas gerem inovações tecnológicas em produtos e processos com velocidade cada vez maior, como forma de garantir sobrevivência no mercado. No setor público, o desafio para uma nova administração pública é o de transformar estruturas burocráticas e hierarquizadas em organizações flexíveis e empreendedoras. As tentativas de inovação na administração pública significam busca da eficiência e da qualidade na prestação de serviços. É necessário romper com modelos tradicionais e implementar uma nova cultura de gestão (GUIMARÃES, 2000).

Desde o início dos anos 80, de acordo com Kettl (1998), observou-se crescer em todo o mundo "uma onda global de reforma do serviço público". Governos de vários países não mediram esforços para modernizar e agilizar a administração pública, dessa forma os países foram pressionados a reduzir o tamanho do Estado. Segundo análise de Bresser-Pereira (1998), a construção deste novo Estado ocorreu como resultado de profundas reformas.

Para Bresser-Pereira (1998), o principal objetivo do Estado era responder às necessidades dos seus cidadãos, como um Estado democrático em que fosse possível aos políticos o acompanhamento da atuação dos burocratas, a estes a obrigação de prestar contas e, aos eleitores, a fiscalização da atuação de ambos. No Brasil, a administração pública gerencial, conforme afirma Bresser-Pereira (1998), surgiu na segunda metade do século passado como resposta à crise do Estado, na busca de superação da administração excessivamente burocrática.

O modelo de administração gerencial foi adotado para enfrentamento da crise fiscal - como estratégia de redução de custo para tornar eficiente os serviços públicos. As principais características desse modelo gerencial são: descentralização do ponto de vista político, com transferência de recursos e atribuições para níveis políticos - regionais e locais; descentralização administrativa por meio da delegação de autoridades para administradores públicos transformados em gerentes autônomos; organizações com poucos níveis hierárquicos; pressuposto da confiança limitada e não da desconfiança; controle por resultados, a posteriori, ao invés de controle rígido passo a passo; e administração voltada para o atendimento ao cidadão.

Esse contexto trouxe novas exigências aos trabalhadores. As mudanças ocorridas nos últimos anos, afetou o contexto do trabalho e demandou o desenvolvimento de novas competências dos profissionais, que contribuíssem para a melhoria de sua performance e, consequentemente, a melhoria da prestação de serviços. Em organizações como o Tribunal de Justiça de Minas Gerais (TJMG), essa realidade não foi diferente. Foi necessário quebrar paradigmas e trabalhar mudanças na busca pela eficiência, celeridade e qualidade dos serviços prestados. Novas competências foram requeridas dos profissionais servidores públicos. Como então formá-los e que novas competências desenvolver?. Este artigo busca avaliar a atuação 
da Escola Judicial Desembargador Edésio Fernandes do TJMG na formação e desenvolvimento de competências profissionais de Juízes.

\section{REVISÃO TEÓRICA}

\section{A Gestão de competências no cenário atual}

Segundo Dutra (2004), a maneira como as organizações atuam na gestão de pessoas tem sofrido inúmeras transformações em todo o mundo, isso devido à inadequação dos modelos tradicionais. A falência das abordagens tradicionais de gestão de pessoas iniciou na década de 60 e se consolidou no início dos anos 80. Na concepção de Dutra (2004), as principais transformações observadas na forma de gerir pessoas, foram: alteração no perfil das pessoas exigido pelas empresas, passando de um perfil obediente e disciplinado para outro autônomo e empreendedor; deslocamento do foco de gestão de pessoas do controle para o desenvolvimento; e maior relevância das pessoas no sucesso do negócio ou da empresa.

Zarifian (2001b) considera que, para a compreensão do significado do conceito de competências, é preciso analisar as mudanças que impactaram a forma e o sentido do trabalho no contexto histórico. A transição de uma civilização agrícola rural para uma civilização industrial urbana afetou profundamente, segundo Zarifian (2001b), a concepção do trabalho. Zarifian (2001b) analisa três mutações principais no mundo do trabalho, que justificam a emergência do modelo de competência para gestão das organizações: a noção de evento, a comunicação e o serviço.

Evento é descrito por Zarifian (2003) como o que ocorre de forma imprevista, não programada, vindo a perturbar o desenrolar normal do sistema de produção. Relaciona-se a atividades de inovação. A comunicação implica em compreender o outro e a si mesmo; significa entrar em acordo sobre objetivos organizacionais. Para Zarifian (2003), "comunicar é tentar entender-se mutuamente, para realizar um acordo tendo em vista um objetivo comum." Assim a comunicação propõe o rompimento com a lógica do posto de trabalho da concepção taylorista-fordista, por meio da socialização de saberes, estimulando o compartilhamento de informações e o estabelecimento de parcerias na busca de soluções conjuntas.

Com a noção de serviço busca-se atender o cliente, externo ou interno da organização, considerando a qualidade final do serviço prestado. Zarifian (2003) considera fundamental o papel dos usuários. "A novidade é que os clientes ou os públicos têm, de fato, o papel de árbitros, até de aliados, freqüentemente involuntários, porque, se a economia do serviço deve avançar, isso se deve também à pressão dos usuários" (ZARAFIAN, 2003). Segundo Zarifian (2003), o desafio atual é sair da lógica do posto de trabalho. É necessário fazer com que de alguma maneira, o trabalho seja reabsorvido pelo indivíduo que o realiza. 0 indivíduo deve preceder o trabalho, tornando-se expressão de sua capacidade de pensamento e atuação, possibilitando-o implicar-se subjetivamente no seu trabalho.

No Brasil, esses dois modelos ainda exercem forte influência nas relações de trabalho das organizações e na formação e educação profissional. No paradigma de produção taylorista-fordista, os requisitos de desempenho no trabalho estavam relacionados às características do cargo e à sua respectiva 
função. Durante décadas, a formação profissional era realizada para preparação técnica aos postos de trabalho, denominada de 'Treinamento Operacional'.

Dessa maneira, a capacitação restringia-se à qualificação. A superação desse modelo exige uma educação diferente, com foco na autonomia em relação ao saber e ao objeto de aprendizagem. Não é suficiente aprender a fazer, é necessário saber o 'porquê', aprender que existem formas diferentes de fazer o trabalho. A educação profissional requer o conhecimento operacional, a compreensão sistêmica do processo, o saber tecnológico, valorização da cultura de trabalho e valores.

No senso comum as pessoas costumam empregar o adjetivo 'competente' para se referir a uma pessoa capaz, que apresenta desempenho adequado, satisfatório. No contexto jurídico, competência é definida como: 'Capacidade, no sentido de poder legal, atribuída a determinado órgão ou autoridade para o conhecimento ou decisão sobre certos atos jurídicos. Extensão do poder de: jurisdição do juiz, isto é, a medida da jurisdição'.

Considerando a realidade organizacional, a palavra competência tem apresentado diversos significados. Durand (1998, citado por BRANDÃO et al., 2001) construiu um conceito de competências baseado em três dimensões interdependentes - conhecimentos, habilidades e atitudes. Competência seria, então, o conjunto de conhecimentos, habilidades e atitudes necessárias à consecução de determinado objetivo. Nos últimos anos, vários autores têm se dedicado a estudar as competências e muitos são os conceitos elaborados. 0 quadro 1, apresenta alguns conceitos encontrados na literatura acadêmica.

Quadro 1: Conceitos de competência.

\begin{tabular}{|l|l|}
\hline \multicolumn{1}{|c|}{ Autor } & \multicolumn{1}{c|}{ Conceito } \\
\hline $\begin{array}{l}\text { Fleury et al. } \\
\text { (2000). }\end{array}$ & $\begin{array}{l}\text { "Um saber agir responsável e reconhecido, que implica mobilizar, integrar, transferir conhecimentos, recursos, } \\
\text { habilidades, que agreguem valor econômico à organização e valor social ao indivíduo". }\end{array}$ \\
\hline $\begin{array}{l}\text { Sant' Anna } \\
(2002) .\end{array}$ & $\begin{array}{l}\text { "Competência é a combinação de múltiplos saberes - saber-fazer, saber-agir, saber-ser - capazes de propiciar } \\
\text { respostas com bom êxito, por parte dos indivíduos, aos desafios advindos dos processos de reestruturação } \\
\text { produtiva e modernização produtivos". }\end{array}$ \\
\hline Zarifian (2003). & $\begin{array}{l}\text { "A competência é uma inteligência prática das situações que se apoia em conhecimentos adquiridos e os } \\
\text { transforma à medida que a diversidade das situações aumenta". }\end{array}$ \\
\hline
\end{tabular}

\section{Estrutura de poderes, o poder judiciário de Minas Gerais e a EJEF}

O Poder Judiciário é um dos três órgãos do Poder do Estado, é autônomo e independente. É formado pelo conjunto de juízes e tribunais destinados a exercitar a função jurisdicional do Estado. É responsável pela aplicação das leis na solução dos conflitos de interesses entre pessoas, empresas, instituições para garantir os direitos de cada um e, consequentemente, promover a Justiça. O Tribunal de Justiça de Minas Gerais é o órgão superior do Poder Judiciário Estadual e tem sede em Belo Horizonte e jurisdição em todo o território do Estado de Minas Gerais.

A Escola Judicial Desembargador Edésio Fernandes (EJEF) foi criada em 1977, destinada à formação inicial e permanente de magistrados. Inicialmente, o modelo adotado para a EJEF foi elaborado pelo Prof. Ricardo Fiúza, a partir de um estágio de um ano (1982-1983) feito por ele no Centro de Estudos Judiciários de Lisboa (CEJ), a Escola da Magistratura de Portugal. A EJEF conta com 170 servidores distribuídos nas gerências e coordenações. São objetivos da atual EJEF: promover ações inerentes à seleção, à formação inicial 
e permanente, integração e acompanhamento dos magistrados, servidores, estagiários, voluntários e colaboradores da justiça; acompanhar o desempenho e administrar as carreiras dos servidores; colaborar, no âmbito de sua competência, com os projetos de extensão e de responsabilidade social do Tribunal bem como gerir a informação documental especializada da Instituição.

O Juiz, segundo pequeno glossário jurídico, é pessoa constituída de autoridade pública para o exercício da função jurisdicional e de administrar a Justiça. "O Juiz deve cumprir e fazer cumprir - com independência, serenidade e exatidão - as disposições legais e os atos de seu ofício; sentenciar ou despachar sem exceder injustificadamente os prazos e determinar as providências para que os atos processuais se realizem nos prazos legais" (TJMG, 2003).

\section{METODOLOGIA}

Com o objetivo de adequar a estratégia aos objetivos dessa pesquisa, foi adotado o método de estudo de caso. A pesquisa em questão tem como objeto de estudo a Escola Judicial Desembargador Edésio Fernandes do Tribunal de Justiça de Minas Gerais. O Universo da pesquisa é constituído pela população formada por magistrados do TJMG, não sendo possível analisar toda a população de juízes da organização, optou-se por selecionar os participantes. A unidade de observação foi constituída por ocupantes do cargo de Juízes de Direito lotados em Varas das Comarcas da capital mineira e três comarcas do interior. A definição dos entrevistados seguiu critérios intencionais, ocorrendo sua seleção por questões tanto de acessibilidade como por questões de tipicidade.

Para realizar a coleta de dados foram utilizados: análise documental, entrevista semiestruturada e observação direta. Na entrevista foi utilizado um formulário com questões abertas e questões medidas por escala tipo Likert, em que o pesquisador anotou as respostas que o entrevistado proferiu verbalmente. Com a finalidade de trabalhar os dados identificados na pesquisa, foi utilizada a análise de conteúdo.

Em uma população de 831 Juízes de Direito da primeira instância do TJMG (capital e interior do estado), foram entrevistados dez ocupantes do cargo, sendo oito do sexo masculino e dois do feminino. Em relação à faixa etária, sete possui idade na faixa dos 41 a 50 anos, um possui menos de 30, um está acima de 51 anos e um na faixa de 31 a 40 anos. Referente à lotação atual dos Juízes, três estão em comarcas do interior, seis estão distribuídos em Varas da comarca de Belo Horizonte (Cível, Fazenda Pública Estadual, Feitos Tributários e outras), um se encontra na corregedoria e um no Juizado Especial da capital. Além do cargo de Juiz de Direito, cinco deles trabalham ou já trabalharam como Professores da EJEF. Quanto ao tempo de atuação no cargo de Juiz, três magistrados ocupam a função há dois anos e, para o restante, a permanência varia de doze a dezoito anos.

\section{Análise das competências requeridas}

Em relação às competências, os entrevistados assinalaram, em uma escala de zero a dez, o grau em que cada competência é requerida para a função de juiz. Para cada competência avaliada foram calculadas as médias entre todos os pesquisados. 0 quadro 3 , apresenta a média das pontuações de cada competência. 
Foram calculadas também as médias das respostas dos juízes em relação a quais competências a EJEF desenvolve, quais ela desenvolve parcialmente e aquelas que necessitam ser desenvolvidas por ela, especificadas no quadro 4.

Quadro 3: Competências: pontuação média.

\begin{tabular}{|l|r|}
\hline \multicolumn{1}{|c|}{ Competências } & Média Pontuação \\
\hline Comunicação, saber ouvir e dialogar & 10 \\
\hline Capacidade de tomar decisões & 10 \\
\hline Gerar resultados efetivos com qualidade & 9,9 \\
\hline Autocontrole emocional, tolerância ao estresse, lidar com frustrações & 9,9 \\
\hline Gerir conflitos & 9,7 \\
\hline Capacidade de conciliação & 9,6 \\
\hline Comprometimento com os objetivos da Instituição & 9,5 \\
\hline Lidar com o "poder" do cargo & 9,4 \\
\hline Domínio de conhecimentos técnico- jurídicos & 9,3 \\
\hline Gerir pessoas, liderar & 9,2 \\
\hline Visão de mundo ampla e global & 9 \\
\hline Lidar com incertezas e ambiguidades & 9 \\
\hline Relacionamento interpessoal, interagir com as pessoas e adaptar-se socialmente & 9 \\
\hline Planejamento, identificar e definir com clareza objetivos e metas para o Escrivão e equipe. & 9 \\
\hline Gerir o tempo, celeridade & 8,7 \\
\hline Lidar com situações novas e inusitadas & 8,4 \\
\hline
\end{tabular}

Quadro 4: Competências desenvolvidas pela EJEF.

\begin{tabular}{|c|c|c|c|c|}
\hline Competências & Desenvolve\% & $\begin{array}{c}\text { Desenvolve } \\
\text { parcialmente\% }\end{array}$ & $\begin{array}{c}\text { Necessita } \\
\text { desenvolver } \\
\%\end{array}$ & $\begin{array}{c}\text { Não } \\
\text { respondeu\% }\end{array}$ \\
\hline Comunicação, saber ouvir e dialogar & 10 & 50 & 20 & 20 \\
\hline Capacidade de tomar decisões & 40 & 20 & 20 & 20 \\
\hline Gerar resultados efetivos com qualidade & 40 & 10 & 30 & 20 \\
\hline $\begin{array}{l}\text { Autocontrole emocional, tolerância ao estresse, } \\
\text { lidar com frustrações }\end{array}$ & 10 & 10 & 60 & 20 \\
\hline Gerir conflitos & 10 & 40 & 30 & 20 \\
\hline Capacidade de conciliação & 10 & 40 & 30 & 20 \\
\hline Comprometimento com os objetivos da Instituição & 50 & 10 & 20 & 20 \\
\hline Lidar com o "poder" do cargo & 10 & 40 & 30 & 20 \\
\hline Domínio de conhecimentos técnico- jurídicos & 60 & 10 & 10 & 20 \\
\hline Gerir pessoas, liderar & 10 & 20 & 50 & 20 \\
\hline Visão de mundo ampla e global & 10 & 30 & 40 & 20 \\
\hline Lidar com incertezas e ambiguidades & 10 & 30 & 40 & 20 \\
\hline $\begin{array}{l}\text { Relacionamento interpessoal, interagir com as } \\
\text { pessoas e adaptar-se socialmente }\end{array}$ & 10 & 30 & 40 & 20 \\
\hline $\begin{array}{l}\text { Planejamento, identificar e definir com clareza } \\
\text { objetivos e metas para o Escrivão e equipe. }\end{array}$ & 10 & 30 & 40 & 20 \\
\hline Gerir o tempo, celeridade & 10 & 30 & 40 & 20 \\
\hline Lidar com situações novas e inusitadas & 10 & 30 & 40 & 20 \\
\hline
\end{tabular}

Em relação às competências desenvolvidas pela EJEF, segundo os juízes entrevistados: Desenvolve bem: 'Domínio de conhecimentos técnico-jurídicos' (60\%); 'Comprometimento com os objetivos da Instituição' (50\%); e duas competências com 40\%: 'Capacidade de tomar decisões' e 'gerar resultados efetivos e com qualidade'. Desenvolve parcialmente (regular): 'Comunicação, saber ouvir e dialogar' (50\%); Três competências com 40\%: 'Gerir conflitos', 'Capacidade de conciliação' e 'Lidar com o poder do cargo'.

Prosseguindo, necessita desenvolver (insuficiente): 'Autocontrole emocional, tolerância ao estresse, lidar com frustrações' (60\%); 'Gerir pessoas, liderar' (50\%). Seis competências com 40\%: 'Visão de mundo ampla e global'; 'Lidar com incertezas e ambiguidades'; 'Relacionamento interpessoal, interagir com as 
pessoas e adaptar-se socialmente'; 'Planejamento, identificar e definir com clareza, objetivos e metas para o Escrivão e equipe'; 'Gerir o tempo, celeridade' e 'Lidar com situações novas e inusitadas'.

Portanto, quatro competências são bem desenvolvidas, quatro são trabalhadas regularmente e oito competências desenvolvidas de maneira insuficiente pela EJEF, segundo os juízes entrevistados. A 'Capacidade de tomar decisões' foi apontada pelos juízes como essencial para sua atividade fim, inclusive podendo interferir na celeridade da justiça. Há alguns questionamentos dos juízes que acreditam haver, por parte da instituição, preocupação com a quantidade e não com a qualidade do serviço prestado. Como não há fiscalização quanto à qualidade do serviço do juiz, segundo um dos entrevistados, a exigência deve ser pessoal.

A competência que mais necessita ser desenvolvida, segundo análise dos juízes (60\%) é o 'autocontrole emocional, tolerância ao estresse e lidar com frustrações'. Há magistrado que defende a ideia de que a EJEF utilize toda a sua estrutura para focar na formação humanística do juiz. Um dos magistrados acredita que a transição do candidato a juiz gera fenômenos "emocionais" que precisam ser trabalhados pela EJEF. O equilíbrio emocional para o Juiz é fundamental na opinião de um dos juízes, pois toda decisão envolve aspectos técnicos, mas também conteúdos emocionais.

A qualidade é importante, mas, muitas vezes o tribunal lista objetivos e prioridades que contrariam isso aqui. É lógico que a gente tem que gerar resultados efetivos com qualidade, mas dificilmente a gente tem meios para fazer isso. Basta ver o número de processos que estão nas secretarias. Na Escola Judicial falaram para mim que o tribunal estava mais preocupado com produção em massa do que com qualidade. E foi um Desembargador quem disse (Entrevistado 1);

O Tribunal só pensa em produtividade, em quantas sentenças eu dou, não quer saber a qualidade do que eu faço. (...) O Tribunal exige que o Juiz dê 300 sentenças por mês e não quer saber do jeito que vai sair. Isso é qualidade? (Entrevistado 2);

O controle emocional é essencialíssimo. As partes já chegam aqui combalidas emocionalmente, então, sem o controle emocional elas vão sair daqui direto pro Raul Soares, ainda mais em Vara de Família, que é pior ainda. Então se você chega lá com clima de hostilizar as partes, que já estão completamente fragilizadas por estarem ali, irá complicar tudo. Eu acho isso importantíssimo (Entrevistado 4);

Quem passa no concurso está preparado para assumir o cargo tecnicamente. Mas a parte humana, as dificuldades, as dúvidas, elas podem ser todas sanadas. Então, acho muito importante que a escola deixe o aspecto técnico de lado e volte toda a sua estrutura, na minha opinião, para a formação humanística, a parte pessoal do juiz, o gerenciamento, a liderança, o comportamento emocional. É o mais importante hoje (Entrevistado 3);

A EJEF deveria trabalhar no Juiz temas relacionados a como lidar com o estresse, atividades de integração, saber conviver em grupo, não se isolar. Deveria promover encontros fora da EJEF em pousadas no fim de semana (Entrevistado 2);

(...) A transição do candidato a juiz precisaria ser mais trabalhada, não do ponto de vista técnico - jurídico, mas do ponto de vista emocional, psicológico, psicanalítico. Acho que deveria haver uma sucessão de módulos de autoconhecimento. No doutorado mesmo, a gente estuda isso. Apesar do meu doutorado ter sido na área jurídica, tive um Módulo de Análise Transacional e outros módulos que trataram desta questão (Entrevistado 7);

O juiz interpreta para decidir, então ele tem que conhecer este processo de decisão e compreender o que motiva sua decisão, não só técnica e juridicamente, mas fundamentalmente emotiva. O dia-a-dia revela que o conhecimento técnico é importante, mas não é uma parcela tão significativa, quanto a parcela de autoconhecimento. Ele precisa diferenciar as duas funções, os dois 'eus', ou seja, tem um fenômeno que é a sinapse que faz com que os hemisférios cerebrais se comuniquem, os neurônios do lado racional e os 
do lado emotivo, fazendo com que as decisões passem por esse diálogo entre razão e sentimento. Então, toda decisão está impregnada de emoções, por mais técnica que ela seja. Ele pode descontar no processo, vamos dizer assim, alguma angústia que ele tenha em relação ao passado dele. Por isso que a neutralidade é um mito, uma farsa (Entrevistado 7, grifo nosso).

A capacidade de conciliação foi identificada como uma competência fortemente requerida. Entre os entrevistados há a opinião de que a cultura da justiça não é conciliatória, mas a maioria considera que a conciliação é o caminho para uma nova justiça mais humanizada. O 'domínio de conhecimentos técnicojurídicos' é a competência mais desenvolvida pela escola judicial, segundo os juízes entrevistados. Os juízes acreditam que a competência de 'Gerir pessoas e liderar' seja relevante para o desempenho de sua função, pouco trabalhada pela escola judicial.

Eu vejo o juiz como um facilitador, uma pessoa que vai contribuir para a solução de problemas alheios. Por isso que eu acho que o investimento em conciliação é fundamental. Você está ali contribuindo para que as partes superem o litígio. Então essa participação depende necessariamente do contato e de uma humanização da justiça (Entrevistado 6);

O sujeito se prepara muitas vezes por dois, três anos para passar num concurso, então o conhecimento técnico-jurídico ele já tem (...) (Entrevistado 3);

Liderança, isso falta na Escola. Há algum tempo tenho insistido nisso. Tenho falado quando eu posso e acho isso importantíssimo, por que juiz lida com pessoas o tempo todo, trabalha com o público, fazendo audiências, com partes, servidores, etc. Então tem que haver uma preparação prévia dessa competência específica, que não existe. Há juízes que lideram efetivamente e outros que não (Entrevistado 3 ).

Há uma cultura na Instituição que reforça a ideia de que a função do juiz seja estritamente técnica e não uma função de liderança. O Escrivão tem o papel gerencial instituído de coordenar as equipes de Escreventes. Há juízes que não assumem o papel de liderança, conforme o primeiro depoimento. Alguns juízes entrevistados defendem a ideia de um curso, módulo ou disciplina de administração pública ou judiciária, a ser realizado tanto na formação inicial como na permanente, considerando que o juiz não tem formação nessa área administrativa:

(...) talvez isso aqui seja mais uma questão voltada para a Secretaria. Nesse caso, por exemplo, eu delego sinceramente esses problemas para minha escrivã. Eu tenho essa confiança, porque nessa parte aqui eu nunca fui bom, chamar atenção, então, eu delego mesmo pra ela (Entrevistado 4);

Acho que o curso da EJEF tinha que evoluir na parte administrativa para criar um módulo de Administração Judiciária, profissionalizar o juiz. Neste sentido deve ter um conjunto de disciplinas, não um conjunto de simplesmente palestras. (...) deveria ter uma programação mesmo, um programa didático pedagógico como se fosse um curso de Administração Judiciária, porque essa é uma competência que deve ser trabalhada. (...) a maioria de nós, e eu me incluo, não tem formação específica na área de administração. (...) Na formação inicial, eu acho que houve uma superficialidade nessas informações, elas poderiam ser aprofundadas e organizadas em um verdadeiro curso de Administração Judiciária (Entrevistado 6).

A maioria dos juízes acredita na importância da competência de 'Relacionamento interpessoal, interagir com as pessoas e adaptar-se socialmente'. No entanto, existe no judiciário uma cultura de que o juiz não possa interagir com as pessoas, em nome da neutralidade. Discrição e postura profissional confundem-se com isolamento, ou seja, para alguns juízes, o relacionamento interpessoal é menos importante. Um dos entrevistados acredita no papel social do Juiz e na necessidade da EJEF em prepará-lo 
nesse aspecto. Um dos entrevistados acredita no papel social do Juiz e na necessidade da EJEF em preparálo nesse aspecto.

A competência de relacionamento interpessoal é fortemente requerida porque o juiz lida com o ser humano o tempo todo (Entrevistado 2);

Eu vejo que muitos juízes entram na Instituição com uma noção diferente do que é ser juiz. Entram em busca de um emprego, de um cargo a mais. Não têm a noção da própria responsabilidade da função, porque a nossa função é muito importante. Nós temos decisões muito sérias. (...) Nós temos um papel relevante na sociedade sobre o aspecto social. Não é só decidir. (...) E a magistratura não é um emprego a mais. Acho que ela é diferenciada e quem não tem essa consciência, essa conscientização dos aspectos humanos, sofre e prejudica mais a própria sociedade. Você fica muito técnico, você só decide com a caneta sem olhar o aspecto social e aí é complicado (Entrevistado 3).

Um dos entrevistados acredita que o volume de processos é incompatível com o número de juízes. Então, organizar e definir prioridades torna-se relevante. Além disso, na opinião desse magistrado, o juiz deveria administrar sua Vara ou Comarca como uma empresa com foco em resultados. A competência 'Lidar com situações novas e inusitadas' de menor pontuação média, ou seja, 8,4, reflete a cultura de resistência às mudanças e inovações. Cabe a EJEF, na opinião dos magistrados, o papel de mudança de cultura da Instituição: 'Quem tem condição de nos dar suporte à evolução é a EJEF. Ela que vai, com certeza, quebrar paradigmas e implantar a cultura de otimização da prestação jurisdicional, verdadeiramente célere e eficaz', afirma o Entrevistado 10.

\section{Análise da atuação da EJEF}

A EJEF é considerada modelo de excelência em relação a outras escolas judiciais no Brasil. Há estados, inclusive, que não possuem escolas preparatórias para juízes e em algumas escolas judiciais o curso preparatório é de pequena duração. Um dos magistrados, participante desta pesquisa, acredita que a Escola acaba formando juízes para outros tribunais de outros estados. Entretanto, há juiz que não acredita que a EJEF contribua após o término do curso de formação inicial.

A EJEF acaba tornando o magistrado mineiro um magistrado diferenciado. O certificado de participação do curso da EJEF tem peso. Outros tribunais se beneficiam disto. A EJEF acaba formando juízes para outros tribunais (Entrevistado 6);

A escola é fantástica, já permitiu, muitos não sabem, que várias sementes que foram lá plantadas, germinassem flores em outros setores. A EJEF é um laboratório de sonhos e realizações. Tudo começa na EJEF (Entrevistado 7);

Para ser franco, depois do curso de formação inicial eu não vejo que a EJEF ofereça condições para o meu desenvolvimento. O que a escola faz? O que eu recebo é algum email convidando para alguma palestra, alguma coisa assim (Entrevistado 1).

A maioria dos entrevistados percebe a escola em um contínuo crescimento, com erros e acertos, mas na busca de aprimoramento constante. Entre os juízes mais novos no cargo que passaram pelo curso de cinco meses, foram apontados vários aspectos positivos: integração e construção de vínculos entre os participantes, troca de ideias, conhecimento da instituição, visitas institucionais, elaboração de sentenças, aspectos administrativos, etc.. A maioria dos juízes pesquisados acredita na importância da prática aliada à teoria no curso de formação. Muitos consideram que a escola tem dado maior ênfase ao conteúdo teórico, faltando maior contato com a prática jurisdicional. O estágio não tem funcionado bem, na opinião de alguns 
juízes, pois falta maior carga horária, plano de estudo com foco em resultado, capacitação dos instrutores do estágio e, ainda, aspectos de organização.

Segundo um dos entrevistados, na Escola de Magistratura do RJ são nomeados juízes orientadores, que funcionam como 'tutores' cujo papel é orientar e acompanhar os juízes novos, não somente durante o estágio, mas também algum tempo depois quando os juízes já estivessem nas comarcas. Os magistrados acreditam na necessidade de um acompanhamento psicossocial para os juízes. Um dos pesquisados defende a ideia de reuniões periódicas entre magistrados e equipe de Psicologia para trabalhar as competências pessoais.

Seria fundamental se a gente pudesse de tempos em tempos reunir com a equipe que trabalha na área de psicologia, sentar, discutir e debater, falar sobre as nossas dificuldades, nossas angústias, trocar experiências com nossos colegas e equipe para formar as competências pessoais. Durante o curso devia ser tratado dessa forma e não no formato de aulas teóricas sobre psicanálise, discussão sobre a formação do mundo pós-moderno, etc. No máximo algo sobre a teoria da psicanálise iria contribuir muito, na minha opinião, para essa formação pessoal. (Entrevistado 6)

Alguns dos juízes entrevistados efetuaram uma crítica em relação à postura dos professores (juízes e desembargadores) em sala de aula. A hierarquia e as relações de poder foram apontadas por alguns juízes como dificultadora da relação professor-aluno. Além disso, essa postura professor-aluno dificultou a possibilidade de troca de conhecimentos.

O curso possibilitou essa troca? Sem dúvida, de forma bem marcante. Em alguns módulos mais que outros. Em função da disciplina ou da postura do professor? Em função da postura. A troca se dá onde há abertura. Nesse sentido o senhor acha que a escola judicial deveria caminhar mais na formação pedagógica dos professores? Sem dúvida, com certeza, esse investimento pedagógico é essencial para a escola. É claro que a experiência da EJEF é pioneira, mas ela não pode ficar prisioneira de seu pioneirismo (Entrevistado 6).

Grande parte dos juízes entrevistados consideram que a EJEF prepara o juiz no curso de formação inicial, mas não investe na formação permanente. Um dos entrevistados faz uma crítica mais severa a EJEF por considerar que ela não estimula os juízes a estudarem e a se desenvolverem. Essa visão de que o juiz tem que ficar no gabinete trabalhando e não se preocupar com seu aprimoramento parece arraigada à cultura da Instituição, ou seja, para alguns juízes esse é o comportamento esperado pelo TJMG.

A Escola Judicial não pode só investir no juiz que vai ingressar na carreira. A formação do juiz tem que ser constante. Quando eu estava fazendo esse curso de pós-graduação e procurei o superintendente da Escola, há alguns anos, ele disse para mim: que 'juiz tem que ficar em gabinete trabalhando e não estudando'. Esse foi o estímulo que recebi de um desembargador, superintendente da Escola Judicial (Entrevistado 2).

Olha eu só sei o seguinte, a gente trabalha tanto, compromete tanto o serviço da gente quando a gente sai para ir a esses encontros (...) Eu acho que o juiz pode ler, pode receber apostila, pode receber tantas formas de ser auxiliado, não necessariamente ter que fazer esses cursos. Chega num momento da vida da gente, também depois de 15 anos de magistrado, que é pouca coisa assim que acrescenta na forma de trabalho, você já cria aquele padrão. Sobre o aspecto técnico é bom participar, mas acho que não é essencial. Ao invés de viajar para congressos, basta ler a jurisprudência atualizada (Entrevistado 4).

Em relação aos 'Encontros Jurídicos Regionais' (ENJUR), a maioria dos entrevistados considera importante este evento como forma de aprimoramento, troca de ideias, melhoria da comunicação e interação entre os participantes. Dentro de uma abordagem de Educação Continuada, aproveitando recursos tecnológicos, há opinião de um dos magistrados que considera a possibilidade de mesclar encontros 
presenciais com encontros virtuais, como forma de otimização, busca de resultados, redução de custos e desdobramentos como cursos, grupos de estudo, etc..

Entre os entrevistados, observa-se que poucos juízes têm participado das palestras e seminários promovidos pela EJEF. Muitos podem ser os motivos para esse comportamento. Segundo um deles, é necessária uma atuação da EJEF na mudança de cultura, estimular o aprendizado constante, a disseminação e o compartilhamento do conhecimento. As palestras acontecem na capital, dificultando a participação dos juízes do interior e os recursos da EJEF são pouco utilizados, na opinião dos entrevistados.

Referente aos cursos de Pós-graduação, há preocupação de um dos juízes entrevistados quanto ao aspecto prático e resultado concreto para a Instituição. Segundo os juízes não há incentivo da EJEF para realização de mestrados ou doutorados. Grande parte dos juízes considera falha a comunicação no TJMG e EJEF. Alguns acreditam que a Instituição e a Escola não divulgam as informações, ou divulgam de forma inadequada. A maioria dos juízes não tem tempo e gostaria que a EJEF pudesse colher as informações importantes e enviar de maneira resumida, simplificada e com rapidez. Há magistrado que considera os veículos de comunicação úteis apenas para promoções pessoais.

Não contribui. Acho a comunicação no TJ falha. Os jornais do TJ e AMAGIS só servem para autopromoção. A Comarca tal foi inaugurada, o Desembargador Fulano de tal recebeu medalha. Ultimamente não leio nada. Chega e eu jogo no lixo. Acho um desperdício de papel. Não adianta a Revista de Jurisprudência. O Juiz não tem tempo (Entrevistado 2).

Muitos acreditam que a EJEF poderia utilizar recursos tecnológicos que dispõe para a veiculação e disseminação de informações úteis aos juízes. Há magistrados que utilizam outros recursos para buscar informações. Experiências e iniciativas de sucesso também poderiam ser divulgadas pela EJEF, assim como uma TV EJEF. O serviço de pesquisa da EJEF na opinião dos juízes entrevistados é pouco utilizado por eles, apesar de haver reconhecimento quanto à ótima prestação do serviço. O principal motivo para não utilizar o serviço, é a urgência na solução dos processos. Ainda assim, um dos magistrados sugere que as pesquisas deveriam ser disponibilizadas pela EJEF, por meio dos recursos tecnológicos, para todos os magistrados.

Quanto ao setor de pesquisa, confesso que nunca utilizei. Revistas, a gente recebe sempre, mas eu utilizo muito pouco, a minha ferramenta de pesquisa maior é o computador e a Internet. Então, para mim pelo menos se a EJEF tivesse no site dela uma ferramenta de busca ou de pesquisa, alguma coisa assim, seria mais útil do que livros, etc. (Entrevistado 8).

Atualmente a EJEF dispõe de recursos tecnológicos como a Vídeo Conferência, página da EJEF, que precisam ser melhor aproveitados, principalmente para atingir um maior número de comarcas do interior, na opinião de um dos entrevistados. Grande parte dos juízes entrevistados é favorável ao Processo Virtual, com benefícios de diminuição de papel (meio ambiente), desburocratização, agilidade, otimização, redução de custo. Entretanto, há posturas de desconfiança e resistência. No entanto, há a exclusão digital e a pessoalidade como aspectos a serem considerados. 
Você sabe que o nosso código de processo é de Roma, enquanto os cientistas estão discutindo o Genoma, nós estamos discutindo cláusulas já decretadas pelos romanos [...]. Os recursos totalmente protelatórios e mais tudo que é fato, os processos que são barrados, as reformas [...]. Então, falar em processo virtual nesse momento, com tanta questão processual para ser solucionada, para ser simplificada, eu não sei. [...]. Com essa legislação processual aí eu acho difícil implantar isso agora [...]. Eu acho que isso está muito longe, ainda, não que eu seja contra (Entrevistado 4).

Venho da área ambiental. Sou um sentimental. Há um desperdício enorme de papel. Essa impressora que está nesta sala, não imprime nos dois lados. Acho que o Processo Virtual irá contribuir muito em termos ambientais, na celeridade, em melhorar o acesso. Por outro lado, não pode transformar em instrumento de exclusão. Tem que ter cuidado. A exclusão digital é uma das mais marcantes formas de exclusão social. Para o desempenho de determinadas funções, o processo virtual será extremamente importante, mas tem que conviver com o sistema convencional por causa da exclusão digital.

Confesso que eu vejo isso com muita simpatia, embora há situações que são altamente complexas. Na área de fazenda, na área tributária, que as coisas se resolvem com documentos, a questão da virtualidade, será de pronto assimilado. Mas em um processo penal em que se lida muito com a pessoalidade, é um processo mais lento (Entrevistado 10).

\section{RESULTADOS E DISCUSSÃO}

A organização judiciária emerge da Administração Científica e Burocrática. Conserva, ainda, em muitas de suas ações, características como a centralização do poder, a hierarquia, a departamentização, o controle, a disciplina, entre outros. Essas características dificultam a comunicação na Instituição, a adaptação a situações novas, a agilidade na solução de problemas e o relacionamento entre pessoas e setores.

Observam-se, contudo, mudanças na organização judiciária mineira que sinalizam a busca pela excelência e profissionalismo no atendimento ao cidadão. Essas mudanças ocorreram a partir da reforma gerencial do Estado, implementada na década de 90, da reforma judiciária mais recente e também das transformações de ordem tecnológica. Além disso, como analisa Zarifian (2003), o conceito de trabalho sofre modificações ao longo do tempo. Até a década de 70 predominavam o modelo de profissão e o posto de trabalho; havia uma separação entre trabalho e trabalhador. As três mutações no mundo do trabalho, apresentados por Zarifian (2001), justificam o modelo de competências para a gestão das organizações: o evento, a comunicação e o serviço. Tais mutações podem ser adotadas como referência para analisar as mudanças que ocorrem no poder judiciário de Minas Gerais.

Numa era de incertezas, observa-se que a organização judiciária também se depara com o novo, o imprevisto, o não programado. Conforme relato de um Juiz: 'no Direito há uma evolução constante e aparecem temas que geram perplexidade na gente'. Conforme observado na pesquisa, há uma certa resistência dos juízes em lidar com situações novas, principalmente em relação aos recursos de natureza tecnológica. Vale destacar que essa resistência também é característica de organizações burocráticas.

A dificuldade na comunicação entre pessoas e setores também está presente nas organizações burocráticas. Isso é uma realidade do judiciário mineiro e igualmente da Escola Judicial. Observa-se que os juízes do interior ficam 'ilhados' e são pouco informados do que acontece na capital. Assim, a comunicação proposta por Zarifian (2001) é fundamental, pois pressupõe a socialização dos saberes, o compartilhamento de informações e o estabelecimento de parcerias. A EJEF pode contribuir para facilitar esta comunicação. 
Zarifian (2003) considera fundamental o papel dos usuários na melhoria da prestação de serviços. Observase ainda que o cidadão/usuário vem adquirindo um papel de destaque, pois contribui para um avanço nos serviços prestados. Percebe-se que no TJMG essa realidade não é diferente. A busca é pela melhoria constante no atendimento à sociedade, ao cidadão, aspecto que a EJEF compartilha.

Segundo Dutra (2004), as organizações estão exigindo uma alteração no perfil profissional dos funcionários, passando de obediente e disciplinado para autônomo e empreendedor, estimulando a iniciativa, a criatividade e a busca autônoma de resultados. Porém, de acordo com a análise de Morgan (1996), o enfoque mecanicista (administração científica e burocracia) tende a rotinizar e a mecanizar a vida humana corroendo o espírito humano e a capacidade de ação espontânea'. Aspectos como iniciativa, criatividade e autonomia não são valorizados pelas organizações burocráticas. Por outro lado, o judiciário tem sido alvo de críticas da imprensa e da sociedade em relação à morosidade da justiça, surgindo a necessidade de fiscalização e controle externo propostos pela reforma judiciária.

A pressão recai sobre o magistrado. A sociedade e a Instituição querem um juiz célere nas decisões, dinâmico e capaz de gerar resultados efetivos. Neste contexto a EJEF, por estar inserida na organização judiciária, sofre as mesmas características da organização burocrática e reforça o modelo vigente. Isso é evidente quando os juízes criticam a relação hierárquica e formal entre professor e aluno e entre professoresjuízes e professores-desembargadores. Neste caso a relação de poder e hierarquia é transposta do TJMG para a EJEF e sala de aula. Caberia, portanto, à EJEF trabalhar a formação pedagógica dos professores de modo a facilitar a relação professor-aluno e estimular o compartilhamento de conhecimentos e experiências, aspecto fundamental para o aprendizado do juiz.

Parte da formação ministrada pela escola apresenta características do modelo taylorista-fordista ao reduzir a qualificação profissional à preparação técnica aos postos de trabalho, restringindo-a ao comportamento esperado e ao 'saber-fazer' (BOTERF, 2003; ZARIFIAN, 2003). Diferentemente no modelo 'Economia do Saber' de Boterf, (2003) o sujeito é o ator e sua atuação vai além do prescrito. Ele deve reagir aos acontecimentos e demonstrar iniciativa e a competência próprias do "saber-agir". Esse modelo corresponde à definição de competência proposta por Zarifian, (2003): "uma inteligência prática das situações que se apoia em conhecimentos adquiridos e os transforma à medida que a diversidade das situações aumenta". Ela deve responder aos eventos e à complexidade.

Boterf (2003) afirma ainda que o desenvolvimento de competências deva ser responsabilidade do indivíduo e não somente da chefia ou organização. A cada um cabe o papel de ator do seu próprio desenvolvimento e a carreira não é mais definida pela organização, mas uma programação individual. Na organização judiciária pesquisada, entretanto, há uma visão paternalista que tende a gerenciar e a controlar o desenvolvimento das pessoas. A estabilidade dos funcionários das organizações públicas é um fator que pode encorajar a acomodação das pessoas em relação ao seu desenvolvimento profissional, contrária à iniciativa privada, onde há o risco da demissão e do desemprego. A competitividade do mercado exige constante atualização dos profissionais, domínio de línguas e de recursos tecnológicos. 
Outro aspecto é a tendência do ensino formal ministrado pela EJEF ser orientado exclusivamente ao 'aprender a conhecer', um dos quatro pilares da UNESCO (DELORS, 2001). Foi constatado pela pesquisa, que a EJEF enfatiza o conhecimento técnico-jurídico em seus cursos de formação inicial e permanente. Para o ingresso na magistratura, os conhecimentos exigidos e avaliados no concurso são os jurídicos. É relevante observar a valorização dada pelos juízes às competências 'humano-sociais' (comunicar, saber ouvir e dialogar, autocontrole emocional, tolerância ao estresse, saber lidar com frustrações, gerir conflitos, conciliar e se relacionar com as pessoas).

Os juízes consideram que, de modo geral, a EJEF desenvolve pouco essas competências e que são imprescindíveis para a atuação deles no exercício de suas funções. A idade mínima para o ingresso na magistratura é de 25 anos. Conforme relato dos juízes, é necessária uma maturidade pessoal e profissional para o exercício da atividade de 'julgar' porque 'toda decisão está impregnada de emoções'. Cada pessoa percebe o mundo sob a sua perspectiva e age conforme seus valores, crenças e história de vida. As questões de ordem pessoal do juiz influenciam na sua tomada de decisão. 'A neutralidade é um mito, uma farsa'. Portanto, torna-se essencial trabalhar esses aspectos emocionais no juiz.

Há uma tendência nas organizações da atualidade em resgatar o 'ser humano'. Segundo Davel et al. (2001), a dimensão subjetiva torna-se fundamental, considerando-se o panorama de mudanças radicais que exigem reflexão, bom senso, sensibilidade e consciência para lidar com o ser humano. As relações dos juízes com o ambiente são de complexidade, fragilidade, efemeridade e contradições. Paralelamente, observa-se na organização judiciária uma busca pela conciliação e pela humanização da justiça. "Isso nos faz repensar a justiça, cuja grande missão, hoje entendemos, ao invés de se alimentar do litígio, é de saciar-se com o entendimento, o acordo, a pacificação de partes potencialmente antagônicas" (SILVA, 2006).

Essa mudança cultural importante aponta para a emergência de um "novo juiz" mais humanizado, facilitador das relações e do diálogo; um juiz mais equilibrado emocionalmente, capaz de ouvir e gerir conflitos e, desta forma contribuir para que as partes encontrem o entendimento e superem o litígio. Contudo, essas competências precisam ser desenvolvidas pela EJEF em caráter permanente. Cabe à EJEF, como instituição educadora "fornecer, de algum modo, os mapas de um mundo complexo e constantemente agitado e, ao mesmo tempo, a bússola que permita navegar através dele” (DELORS, 2001). É relevante desenvolver no juiz o 'aprender a ser' e o 'aprender a conviver', buscando o autoconhecimento, a compreensão do outro, a percepção das interdependências, a capacidade de dialogar, o respeito pelos valores do pluralismo, da compreensão mútua e da paz (DELORS, 2001).

Há outros entraves que dificultam esta humanização do juiz, a começar pelo volume enorme de processos a serem sentenciados e a pressão da Instituição para baixar o volume processual, sem a preocupação com a qualidade do trabalho realizado. Aqui prevalece o 'juiz-máquina', característica das organizações mecanicistas, ou como foi dito, do 'juiz que só decide com a caneta'. Em nome desta 'produção em massa', exigida do Juiz, ele não dispõe de tempo para estudar e de condições para ampliar seus conhecimentos, pois segundo um dos entrevistados: 'Juiz tem que ficar no gabinete trabalhando e não 
estudando'. Aqui desconsidera-se o juiz 'ser humano' e a necessidade de contínuo aprendizado e desenvolvimento como pessoa e como profissional.

Este 'modelo mental' parece incorporado à cultura da Instituição. Existem muitos juízes que não participam dos eventos propostos pela EJEF. É papel da escola judicial mudar esta cultura e estimular a busca contínua do conhecimento. Para Dutra (2004), o grande desafio para a gestão das organizações é gerar e sustentar o comprometimento das pessoas, que só é possível se elas perceberem que sua relação com as organizações Ihes agrega valor. $\mathrm{O}$ indivíduo deve preceder o trabalho, implicar-se subjetivamente no seu trabalho (ZARIFIAN, 2003). 'Saber o porquê' é uma forma de dar ao indivíduo sentido e significado ao trabalho que desenvolve. É fundamental a consciência do magistrado em relação ao seu trabalho, sua missão e compromisso com a justiça e com a paz social.

Outro resultado importante na pesquisa é o reconhecimento por parte dos juízes do seu papel de líderes. Isso representa uma importante mudança de cultura. Até há pouco tempo o juiz era visto como um técnico responsável por processar, julgar causas e sentenciar. Há 'juízes empresários' que tratam suas varas como empresas, definem estratégias, planejam e trabalham com foco em resultados. Contudo, há juízes que, pela dificuldade em liderar e por falta de preparo gerencial, delegam essa função para seus Escrivães. Segundo Joaquim Falcão, Diretor da Escola de Direito do Rio de Janeiro Fundação Getúlio Vargas (Gestão 2006), "o juiz necessita de conhecimentos nem sempre ligados ao Direito. É necessário e urgente um programa de formação de juízes que os capacitem para tarefas gerenciais e estratégicas" (FGV, 2006).

Apesar de muitas críticas, há o reconhecimento por parte dos magistrados na excelência da Escola Judicial mineira, servindo de modelo e referência para outras escolas no país. Ela tem se destacado em muitas iniciativas. Porém, 'a EJEF não deve ficar refém de seu pioneirismo', precisa buscar o constante aprimoramento de seu trabalho.

\section{CONCLUSÕES}

Na pesquisa em questão, buscou-se identificar as competências requeridas pelos juízes de direito no exercício de sua atividade. Além da identificação das competências, os juízes analisaram a atuação da EJEF no desenvolvimento de cada competência. Acrescentando-se a isso, foram avaliados aspectos positivos e restritivos da atuação da EJEF referente à formação inicial e formação permanente dos juízes, comunicação, informação e recursos tecnológicos.

Características comuns às organizações burocráticas como centralização de poder, hierarquia e controle, são transpostas para as salas de aula, dificultando a relação professor-aluno na Escola Judicial. Em uma organização judiciária antiga, tradicional e conservadora como o TJMG, é papel importantíssimo da EJEF trabalhar a mudança de cultura, ou seja, desmistificar as relações de poder e hierarquia, focar nas metas e nos resultados, sensibilizar para a importância das inovações tecnológicas, trabalhando não só o juiz, mas outras lideranças e todos os servidores, facilitar a comunicação e o relacionamento entre pessoas e setores.

Paralelamente a um juiz dinâmico e atuante, comprometido com resultados, espera-se também um juiz mais humanizado, atento às diversidades, complexidades, compromissado com a dimensão social e a 
busca da pacificação. Assim, é importante que a EJEF possibilite o desenvolvimento de conhecimentos, habilidades, atitudes e valores que conduzam o juiz a um exercício profissional competente. Não basta disseminar o conhecimento, mas estimular o seu compartilhamento. Também criar condições para o juiz desenvolver suas potencialidades, ampliar sua visão, desenvolver sua capacidade para resolver problemas complexos, trabalhar a comunicação, incentivar sua iniciativa e criatividade. Possibilitar crescente grau de autonomia intelectual ao juiz de modo que ele monitore seu próprio desenvolvimento pessoal e profissional.

Pode se concluir que o grande desafio da EJEF é olhar para o futuro e desenvolver um novo paradigma que transcenda e extrapole as fronteiras tradicionais de sua atuação. Neste sentido, a EJEF pode contribuir para o desenvolvimento de novas visões e novas lideranças, que facilitem o processo de transformação contínua. Estimular o aprender a aprender sempre.

\section{REFERÊNCIAS}

BOTERF, G. L.. Desenvolvendo a competência dos profissionais. 3 ed. Porto Alegre: Bookman, 2003.

BRANDÃO, H. P.; GUIMARÃES, T. A.; ANDRADE, J. E. B.. Competências profissionais relevantes à qualidade no atendimento bancário. Revista de Administração Pública, Rio de Janeiro, v.35, n.6, p.61-81, 2001.

BRESSER-PEREIRA, L. C.. Gestão do setor público: estratégia e estrutura para um novo Estado In: BRESSER-PEREIRA, L. C.. Reforma do estado e administração pública gerencial. Rio de Janeiro: FGV, 1998. p.21-38.

DAVEL, E.; VERGARA, S.. Gestão com pessoas, subjetividade e objetividade nas organizações. In: DAVEL, E.; VERGARA, S.. Gestão com pessoas e subjetividade. São Paulo: Atlas, 2001.

DELORS, J.. Educação: um tesouro a descobrir. 6 ed. São Paulo: Cortez, 2001.

DELORS, J.. Educação: um tesouro a descobrir. 6 ed. São Paulo: Cortez, 2001.

DUTRA, J. S.. Competências: conceitos e instrumentos para a gestão de pessoas na empresa moderna. São Paulo: Atlas, 2004.

FGV. Fundação Getúlio Vargas. A reforma silenciosa da justiça. Rio de Janeiro: FGV, 2006.

FLEURY, A.; FLEURY, M. T. L.. Estratégias empresariais e formação de competências: um caleidoscópio da indústria brasileira. São Paulo: Atlas, 2000.

FLEURY, M. T. L.; OLIVEIRA JUNIOR, M. M.. Aprendizagem e gestão do conhecimento. In: FLEURY, M. T. L.; OLIVEIRA JUNIOR, M. M.. As pessoas na organização. São Paulo: Editora Gente, 2002. p.133-146.

GUIMARÃES, T. A.. A nova administração pública e a abordagem da competência. Revista de Administração Pública, Rio de Janeiro, v.34, n.3, p.125-40, 2000.
HAMEL, G.; PRAHALAD, C. K.. Incorporado a perspectiva da competência essencial In: HAMEL, G.; PRAHALAD, C. K.. Competindo pelo futuro. Rio de Janeiro: Campus, 2001. p.257-274.

KETTL, D. F.. A revolução global: reforma da administração do setor público. In: BRESSER-PEREIRA, L. C.; SPINK, P.. Reforma do estado e administração pública gerencial. Rio de Janeiro: FGV, 1998. p.75-98.

MORGAN, G. A.. Mecanização assume o comando: as organizações vistas como máquinas. In: MORGAN, G. A.. Imagens da organização. São Paulo: Atlas, 1996. p.21-41.

SANT'ANNA, A. S. Competências individuais requeridas, modernidade organizacional e satisfação no trabalho: uma análise de organizações mineiras sobre a ótica de profissionais da área de administração. Tese (Doutorado em Administração) - Universidade Federal de Minas Gerais, Belo Horizonte, 2002.

SILVA, A. H.. Ementário de jurisprudência: anexo especial: Dia da Justiça. In: TJMG. Tribunal de Justiça de Minas Gerais. Ementário anual. Belo Horizonte: TJMG, 2006. p.1.

TJMG. Tribunal de Justiça de Minas Gerais. Programa conhecendo o judiciário: o poder judiciário em Minas Gerais. Belo Horizonte: TJMG, 2003.

ZARIFIAN, P.. A gestão da e pela competência. In: SEMINÁRIO INTERNACIONAL EDUCAÇÃO PROFISSIONAL, TRABALHO E COMPETÊNCIAS. Anais. Rio de Janeiro: SENAI, 1998.

ZARIFIAN, P.. O modelo da competência: trajetória histórica, desafios atuais e propostas. São Paulo: Senac, 2003.

ZARIFIAN, P.. Objetivo competência: por uma nova lógica. São Paulo: Atlas, 2001. 